\title{
Currículos disciplinares na área de saúde: ensaio sobre saber e poder*
}

Verônica Santos Albuquerque ${ }^{1}$ Rodrigo Siqueira Batista Suzelaine Tanji3 Edneia Tayt-Sohn Martuchelli Moço ${ }^{4}$

ALBUQUERQUE, V.S. et al. Discipline curricula in the health area: an essay on knowledge and power. Interface - Comunic., Saude, Educ., v.13, n.31, p.261-72, out./dez. 2009.

The present paper provides a historical review regarding knowledge and power construction, taking disciplinary organization as the basis for the discussion about the confinement of knowledge to disciplines in health professionals' education, and its consequences to the ways of delivering healthcare. Interdisciplinarity, transdisciplinarity and complex thought are proposed as theoretical principles to overcome the disciplinary logic.

Keywords: Interdisciplinarity. Transdisciplinarity. Complexity. Curriculum. Health personnel. Knowledge.
O presente artigo traz uma revisão histórica sobre a construção do conhecimento e do poder a partir da organização disciplinar como base para a discussão do confinamento do saber em disciplinas na formação dos profissionais de saúde e suas consequências nos modos de produzir atenção à saúde. Ato contínuo, propõe a interdisciplinaridade, a transdisciplinaridade e o pensamento complexo como referenciais teóricos para ultrapassagem da lógica disciplinar.

Palavras-chave: Interdisciplinaridade. Transdisciplinaridade. Complexidade. Currículo. Profissionais de saúde. Conhecimento.

\footnotetext{
*Artigo original, com base ensaio em puramente teórico, sem qualquer envolvimento de dados gerados a partir de pesquisa com seres humanos. Por isso, não foi submetido a parecer de Comitê de Ética em Pesquisa.

${ }^{1}$ Curso de graduação em Enfermagem, Centro Universitário Serra dos Órgãos (UNIFESO). Avenida Alberto Torres, $111 / 5^{\circ}$ andar, Alto, Teresópolis, RJ, Brasil. 25.964-004 veronicatere@gmail.com ${ }^{2}$ Curso de graduação em Medicina, UNIFESO. ${ }^{3}$ Curso de graduação em Enfermagem, UNIFESO.

${ }^{4}$ Centro de Ciências da Saúde, UNIFESO.
} 


\section{Considerações iniciais}

A formação superior dos profissionais de saúde foi, de modo geral, historicamente construída sobre a fragmentação de conteúdos e organizada em torno de relações de poder, as quais conferiram ao professor especialista uma posição de centralidade no processo de ensino-aprendizagem. Essa construção - entre outros aspectos, tais como o enfoque privilegiado nos determinantes biológicos, na doença e no trabalho hospitalar - vinculou-se à excessiva especialização e ao distanciamento dos conteúdos curriculares necessários à formação de um profissional de saúde com perfil capaz de responder às necessidades da população (Feuerwerker, 2002). Tal dificuldade relaciona-se com o perfil dos egressos, fruto de uma formação que, por um longo tempo, privilegiou a especialização, o uso intensivo de tecnologia e os procedimentos de alto custo, enquanto acumulavam-se as necessidades básicas de saúde de grande parte da população brasileira. Neste âmbito, abordagens que se referem à ética, à humanização e ao cuidado são colocadas em segundo plano (Rêgo et al., 2007).

Estas questões se intensificaram ainda mais nas últimas décadas, justificando o esforço do Ministério da Saúde no sentido de reorganizar a atenção à saúde - na lógica da integralidade do cuidado -, o qual tem sido obstaculizado pela precária disponibilidade de profissionais com formação generalista, dotados de visão humanística e preparados para prestar cuidados contínuos e resolutivos às pessoas (Brasil, 2005). Dentre os inúmeros fatores que contribuem para o descompasso entre a formação em saúde e as necessidades de saúde brasileiras, surgem três aspectos cruciais: (1) A falta de integração entre o ensino básico e o profissionalizante, (2) a formação de profissionais cada vez mais especializados e despreparados para uma atenção generalista, e (3) o ensino fragmentado em inúmeras disciplinas, que tantas vezes induz precocemente à formação profissional especializada (Rodrigues, Reis, 2002).

Frente a esse cenário, experiências transformadoras, desenvolvidas em algumas instituições de Ensino Superior brasileiras, vislumbram a formação do profissional de saúde capaz de prestar cuidado integral a indivíduos e coletividades, entendido como aquele que considera a capacidade de escuta, acolhimento, construção de vínculos e responsabilização (Pinheiro, Mattos, 2006). As novas maneiras de organizar a prestação de serviços e formação em saúde precisam levar em conta as necessidades dos usuários. Assim, a compreensão do ser humano e do processo saúde-doença passa necessariamente por uma abordagem interdisciplinar - e, mesmo, transdisciplinar - na construção dos conhecimentos. Essa abordagem interdisciplinar implica a ultrapassagem das fronteiras entre as disciplinas - espaços de confinamento por excelência - e a articulação dos processos de ensino-aprendizagem ao trabalho e à pesquisa. Com efeito, várias são as estratégias adotadas pelos cursos de graduação na área da saúde que optaram por transformar seus currículos, cabendo mencionar: (1) A ruptura com as "grades" disciplinares, (2) a opção por estruturas modulares integradas, (3) o desenvolvimento de atividades transversais, e (4) as experiências de práticas interdisciplinares, dentre outras (Albuquerque et al., 2007; Rezende et al., 2006; Dellaroza, Vanucchi, 2005; Lima, Komatsu, Padilha, 2003; Feuerwerker, 2003).

Considerando essas experiências, surge a necessidade de se refletir sobre a lógica da organização disciplinar dos currículos para as graduações na área da saúde, como modo de criticá-la e transpô-la, na perspectiva de se desenharem novos sentidos para a formação. Tal é a proposta do presente ensaio, organizado em torno da reflexão histórico-conceitual acerca da disciplina - delimitando-se, especialmente, seu emprego em termos educacionais na formação do trabalhador de saúde -, bem como das possibilidades de superação de sua lógica na formação em saúde.

\section{A histórica construção do conhecimento e do poder a partir da organização disciplinar}

O vocábulo 'disciplina' tem díspares acepções possíveis. De fato, de acordo com Houaiss (2001, p.653), pode ser definida como:

(1) ensino e educação que um discípulo recebia do mestre; (2) obediência às regras e aos superiores; (3) regulamento sobre a conduta dos diversos membros de uma coletividade, imposto ou aceito democraticamente, que tem por finalidade o bem-estar dos membros e o 
bom andamento dos trabalhos; (4) ordem, bom comportamento; (5) obediência a regras de cunho interior; firmeza, constância; (6) castigo, penitência, mortificação; (7) ramo do conhecimento; ciência, matéria.

Ainda que o sentido apresentado no item " 7 " seja aquele usualmente empregado nas discussões de cunho educacional, as conotações expostas nos itens " 3 " e " 4 " têm particular importância ao se reconhecer a disciplina como um modo segundo o qual se organiza a sociedade. De fato, em concordância com Foucault e Deleuze, a constituição de uma sociedade disciplinar é sucessora das sociedades de soberania, instituída após Napoleão ter "operado" a grande conversão de uma a outra (Deleuze, 1992). A emergência da sociedade disciplinar diz respeito à própria evolução do capitalismo, estando em profunda interseção com os modos de produção estabelecidos no período ulterior à Revolução Industrial, a qual é marcada pela organização em termos de espaços de confinamento - cujo projeto ideal pode ser reconhecido na fábrica (Siqueira-Batista, 2007): concentrar, distribuir no espaço, ordenar no tempo, compor no espaço-tempo uma força produtiva cujo efeito deve ser superior à soma das forças elementares -, nos quais a disciplina é exercida de forma institucionalizada, em espaços fechados, havendo necessidade de se passar de um para o outro ao longo da vida:

O indivíduo não cessa de passar de um espaço fechado a outro, cada um com suas leis: primeiro a família, depois a escola ("você não está mais na sua família"), depois a caserna ("você não está mais na escola"), depois a fábrica, de vez em quando o hospital, eventualmente a prisão, que é o meio de confinamento por excelência. (Deleuze, 1992, p.219)

A organização da sociedade disciplinar articula-se ao entendimento de que o sujeito, ao longo de sua vida e sua história, encontra-se submetido a espaços de confinamento, sendo alvo de discursos institucionalizados, sobretudo por meio da educação formal, a qual se constitui como normalizadora e homogeneizadora por excelência, onde a disciplina faz sustentar um tipo específico de conduta esperado pela sociedade por intermédio da organização de sua rotina e do estabelecimento de relações hierárquicas. Com efeito, os confinamentos são moldes, nos quais se estabelecem relações de poder em diferentes domínios (Siqueira-Batista, Siqueira-Batista, 2009). De fato, Foucault reconhece que o poder sobre a vida nas sociedades modernas se estabelece em dois polos - anátomo-política do corpo e biopolítica das populações -, os quais são interconectados por múltiplas redes de relações (Foucault, 1977). A anátomo-política do corpo diz respeito ao desvendamento e produção de discursos e práticas sobre o corpo humano - abordado como máquina a ser otimizada, disciplinada em sua docilidade e produtividade - ao passo que a biopolítica das populações é dirigida aos elementos biológicos e sociais, tais como reprodução, nascimento e morte. Ambas as dimensões - o indivíduo (anátomo-política do corpo) e a massa (biopolítica das populações) - são dispositivos, compatíveis entre si, da organização disciplinar.

Esses ordenamentos foram bastante propícios ao desenvolvimento da especialização de caráter disciplinar em concordância com o desenvolvimento da ciência e da técnica experimentados a partir do século XIX. Tal enfoque disciplinar - como fruto típico do racionalismo científico -, dividiu a universidade em três grandes áreas - a tecnológica, a biológica e a humana - as quais, por sua vez, se estilhaçaram em dezenas de sub-ramos e especializações. Sobre esse aspecto, Crema (1993) chama a atenção para o desenvolvimento do método analítico de Descartes na superação do paradigma escolástico aristotélicotomista medieval da época:

Para aquele momento, o resgate da razão e da objetividade científica foi saudável e as especializações foram criadas na tentativa de acompanhar o acúmulo crescente do saber-efazer humano, que acabaram por sepultar o 'homem pluriapto' ou 'homem total'. Assim, nos últimos quatro séculos, passou-se à especialização das mentes. Surgiram os 'experts nas partes', os 'videntes do mínimo', que no início cumpriram uma função sócio-cultural necessária e fundamental. Mais tarde, entretanto, o movimento passou a ocorrer por puro 
condicionamento dissociativo. Ser especialista adquiriu status, mas a desconexão cada vez maior da visão global, tornou-o um sofisticado 'prisioneiro das frações'. (Crema, 1993, p.138)

Com efeito, se, no campo epistemológico, a disciplina se caracteriza por cada um dos ramos (especializações) do conhecimento, no domínio pedagógico o termo disciplina indica as atividades de ensino ou o ensino de uma área do conhecimento, instaurando a ênfase em informações isoladas que passam a valer por elas mesmas, e não por sua capacidade de ajudar o homem a compreender o mundo, sua realidade e a posicionar-se diante de seus problemas vitais e sociais (Luck, 2001).

Com base nas presentes considerações, pode-se inferir que o campo das relações entre poder e organização disciplinar da construção do conhecimento apresenta muitas variáveis. Tantas são elas e de tal força que a proposta de ultrapassar as disciplinas demanda uma profunda reflexão social, histórica e coletiva, de maneira a sair do contexto da escola para o contexto da vida, da forma como os sujeitos se relacionam e de como este modo de operar pode ser (re)contextualizado.

\section{Estrutura disciplinar, fragmentação do saber e especialização na formação em saúde}

Uma vez realizada a reflexão sobre as concepções de 'disciplina' e a relação entre organização educacional, hierarquia e poder, torna-se factível analisar a estrutura dos currículos formadores de profissionais da saúde, majoritariamente, baseados em grades disciplinares.

A formação superior dos profissionais de saúde, parte integrante do sistema educacional brasileiro, tem sua inspiração no modelo industrial, que, segundo Mosé (2008), é como uma linha de montagem de uma fábrica: as diversas disciplinas, sem conexão umas com as outras, são partes de um mundo que está distante do estudante. Assim, a vida e o contexto ficam afastados dos espaços formadores, que mais parecem um presídio de alunos. Com esta configuração, a educação é essencialmente passiva, fundada no acúmulo de dados e os espaços de formação que, além de isolados do mundo e da vida, nomeiam de "grade" o currículo e de "disciplina" os conteúdos.

A maior parte dos currículos dos cursos de graduação na área da saúde se organiza, ainda hoje, em uma estrutura disciplinar, na qual os ciclos básicos e profissionais são completamente separados. As disciplinas são fragmentadas e estanques e, geralmente, incapazes de aproveitar as referências correlatas entre algumas delas. Nestes termos, as disciplinas são pensadas nos planos dos saberes e dos conteúdos. Assim, os currículos por disciplinas ordenam as ações dos corpos - onde se deve estar, fazendo o quê, em que momento, com quem - tornando o mundo uma disciplinar 'colcha de retalhos' (Veiga Neto, 2002).

Outro fenômeno de grande importância nesta análise diz respeito à atribuição de valor às diferentes disciplinas. Em geral, as disciplinas que lidam com os aspectos biológicos e com as intervenções no corpo, mediadas por procedimentos, são espaços que recebem maior investimento por parte da comunidade acadêmica. Pouca atenção está voltada àquelas que propõem reflexões e ações no campo da ética, das humanidades, do ambiente, das relações interpessoais, intrapsíquicas e das interações sociais.

Assim sendo, a seleção e o modo de operar os conteúdos, calcados nas disciplinas, explicam por que os profissionais de saúde, uma vez formados, (1) direcionam sua prática às especializações, (2) dedicam mais atenção aos problemas de saúde individuais do que aos coletivos, e (3) deixam em segundo plano os fatores psíquicos, afetivos, históricos, culturais e ecológicos do adoecer humano, muitas vezes negando-os como elementos centrais na construção das alternativas de cuidado (Siqueira-Batista et al., 2009; Saippa-Oliveira, Koifman, Pinheiro, 2006).

Nesse cenário o que se observa é que cada disciplina confina seus saberes e compartimentaliza os conteúdos, impossibilitando, na maioria vezes, o exercício da conexão entre os conhecimentos por parte do profissional de saúde em formação. Isso impacta no perfil do profissional, que se constrói naturalmente a partir de um paradigma reducionista e fragmentado. Implica, certamente, a conformação da sua visão do mundo e as suas práticas de atenção à saúde das pessoas. Saippa-Oliveira, Koifman e Pinheiro (2006) concordam que as disciplinas pensadas de modo compartimentalizado conferem caráter unidimensional aos conhecimentos, criando uma visão reduzida e recortada de determinada temática. 
Esse modelo linear, cuja organização prevê o domínio de cada disciplina como requisito para estudantes e professores - e também como conjunto de rituais, rotinas e linguagens criado entre estes atores -, contribui decisivamente para a definição e legitimação daquilo que é considerado saber autêntico e aceitável. Dessa forma, as disciplinas tornam-se as principais maneiras de se analisar e intervir na realidade. Em geral, poucos são os estudantes que conseguem vislumbrar algo que permita unir ou integrar os conteúdos ou os trabalhos das diferentes disciplinas, uma vez que estas se apresentam claramente separadas umas das outras, fragmentando e isolando os conteúdos. O conhecimento tão somente acadêmico e informativo é priorizado, permitindo que os saberes surjam de modo descontextualizado e aparentemente desprovido de qualquer ideologia (Santomé, 1998).

Essa compartimentalização - a qual entende os campos de conhecimento como dimensão desconectada das realidades de saúde da população -, impacta na relação da universidade com a sociedade, como aponta Santos (1997) ao dizer que a universidade não poderá promover a criação de comunidades interpretativas na sociedade se não as souber criar no seu interior, entre docentes, estudantes e funcionários. Para isso é preciso impor, às barreiras disciplinares e organizativas, uma pressão constante, buscando, no fundo, subvertê-las.

Contrariando essa ideia de confinamento disciplinar dos saberes, a segunda metade do século XX e o alvorecer do século XXI têm mostrado que o conhecimento deve receber tratamento multidimensional, ao se reconhecer a complexidade da sociedade contemporânea e a existência de diferentes valores, presentes nas questões humanas, científicas e sociais. A relação mais estreita entre os conteúdos que são trabalhados nos currículos e as necessidades dos estudantes é desejada, de maneira que possam ser empregadas em diferentes contextos e situações profissionais cotidianas.

$\mathrm{Na}$ atualidade, reitera-se, com intensidade, a posição central ocupada pela disciplinaridade, tornando necessária a construção de processos mediatizados pela subjetivação, em um novo formato, que considere a abertura da academia aos movimentos de passagem de uma estrutura disciplinar para alternativas mais abertas, matizadas pela flexibilização e pela rediscussão das relações de poder, as quais permitam repensar a formação de profissionais para atuar, de modo mais fecundo, no tempo e no espaço vigentes (Veiga Neto, 2005).

\section{Ultrapassagem da lógica disciplinar na formação em saúde: interseções e resistência}

Como visto anteriormente, a organização disciplinar na formação em saúde apresenta os conhecimentos fragmentados e fora de contexto, induz a uma formação reducionista, recortada e procedimento-centrada dos profissionais de saúde, além de favorecer o pensamento unidimensional. Com base nesses aspectos, optou-se por refletir sobre a ultrapassagem da lógica disciplinar com base em dois referenciais: (1) a inter/trans/metadisciplinaridade e (2) a complexidade.

\section{Interdisciplinaridade, transdisciplinaridade e metadisciplinaridade}

Os termos interdisciplinaridade e transdisciplinaridade são extremamente polissêmicos. Para delimitar-se melhor tais elementos, cabe distingui-los entre si - e também em relação à multidisciplinaridade:

[...] a abordagem multidisciplinar é o olhar de várias disciplinas específicas sobre um mesmo problema, isto é, pontos de vista diferentes que produzem objetos teóricos diferentes. A interdisciplinaridade é a utilização de vários pontos de vista, mas com a finalidade cooperativa de construir um objeto teórico comum. Por fim, a transdisciplinaridade é o atravessamento das fronteiras disciplinares, consideradas limitadas para dar conta do problema. (Schramm, 2002, p.38)

Com efeito, a interdisciplinaridade se dispõe como configuração de modos de trabalhar com encontros, diálogos e conexões entre os saberes (Pombo, 2005). Assim, a discussão de 
interdisciplinaridade no campo de formação em saúde exige um referencial mais próximo à ideia de atitude, como apresenta Fazenda (2003): atitude de buscar alternativas para conhecer mais e melhor; atitude de reciprocidade que impele à troca, ao diálogo com pares idênticos, com pares distintos ou consigo mesmo; atitude de humildade diante da limitação do próprio saber; atitude de perplexidade ante a possibilidade de desvelar novos saberes; atitude de desafio diante do novo; atitude de responsabilidade, envolvimento e comprometimento com os projetos e as pessoas.

Considerando a compreensão proposta para interdisciplinaridade, a ultrapassagem da lógica disciplinar de estruturação curricular - que passa a integrar não só os conteúdos das diversas áreas do saber, mas, também, os diferentes profissionais da saúde -, se entrelaça às discussões sobre as práticas e os "atos" corporativos: Vive-se um momento histórico em que as corporações das profissões da saúde empreendem um movimento conservador em relação às suas competências específicas. No entanto, a interdisciplinaridade exige um debate sério e honesto, sobretudo quando se parte do princípio da integralidade como eixo nuclear nas mudanças na formação e nos modelos de atenção à saúde.

Embora a experiência de ultrapassar o modelo disciplinar traga conflito e desconforto, ao desestabilizar dispositivos de segurança e relações de poder, possibilita a recondução ao prazer da descoberta, a ampliação da visão de mundo e novas possibilidades de atuação, tanto na esfera do ensino, quanto do trabalho em saúde.

Esse movimento de tornar cada vez mais tênues as fronteiras entre as disciplinas faz emergir conceitos, como o de transdisciplinaridade. Japiassu (2006, p.13) apresenta esse conceito como "a abordagem científica, cultural, espiritual e social dizendo respeito ao que está entre as disciplinas, através das disciplinas e além de toda disciplina".

A atitude transdisciplinar apresenta-se no grau máximo de relações na integração de disciplinas, que permitem a interconexão dos conteúdos no sentido de auxiliar na unificação dos conhecimentos e compreensão da realidade. Essa atitude "transgride a dualidade que se opõe ao binário simplificador e é capaz de articular sujeito/objeto, subjetividade/objetividade, matéria/consciência, simplicidade/ complexidade, unidade/diversidade ou masculino/feminino" (Moraes, 2004, p.215).

A transdisciplinaridade torna-se, pois, uma resposta adequada à globalidade, à contextualização e à necessidade de resposta a problemas complexos e fundamentais da existência:

Donde a necessidade e a urgência, nos dias de hoje, para uma reforma do pensamento e da educação, não somente de procurarmos integrar e religar as diversas disciplinas de nosso saber em quadros de pensamento suscetíveis de corresponder aos grandes problemas que nos colocamos e que nos desafiam, mas de valorizarmos os conhecimentos multi e interdisciplinares e promovermos o desenvolvimento no ensino e na pesquisa, de um espírito ou mentalidade propriamente transdisciplinar. Porque num mundo em que ninguém parece entender ninguém, torna-se imprescindível que abandonemos a rotinização e as falsas seguranças de que ainda se vangloriam nossas disciplinas isoladas e nos entreguemos ao sonho da aventura transdisciplinar apresentando-se como um meio de compensar as lacunas do pensamento científico mutilado pela especialização e exigindo a restauração de um pensamento globalizante em busca da unidade, por mais utópica que possa parecer. (Japiassu, 2006, p.17)

Cabe ressaltar que a proposta inter/transdisciplinar não significa negar cegamente as disciplinas, nem ser contrário às especializações. Nesse sentido, Crema (1993, p.140) propõe uma reflexão sobre a transdisciplinaridade como uma "abertura do especialista ao todo que o envolve e à dialogicidade com outras formas de conhecimento e visões do real, visando a complementaridade". Postula-se a motivação e a disponibilidade para o desafio da convivência com a diversidade e do trabalho em equipe. A proposta é transmutar o especialista fechado na especialidade, transformá-lo num construtor de pontes, consciente da dinâmica do 'todo' e das 'partes', que seja capaz, além de fracionar, de vincular e de restaurar. Nestes termos, a transdisciplinaridade "nasce e é construída da necessidade, interna ao desenvolvimento científico, de religação dos saberes, sem o que se torna impossível conhecer e entender os fenômenos que se revelam campos complexos, de múltiplos fatores e interações" (Severino, 2002, p.29). 
Em recente estudo, Zaballa acrescenta ao debate o conceito de metadisciplinaridade, o qual tem como ponto de apoio a superação da visão disciplinar. Nessa proposição, as disciplinas não são, em nenhum momento, o objeto de estudo, mas instrumentos ou meios para se alcançarem objetivos pretendidos. Na universidade, a metadisciplina deve ser entendida como "a ação de se aproximar dos objetos de estudo a partir de uma ótica global que tenta reconhecer sua essência e na qual as disciplinas não são o ponto de partida, mas sim o meio que dispomos para conhecer uma realidade que é global e holística" (Zaballa, 2002, p.34).

De um modo prático, podemos vivenciar essa transposição da lógica disciplinar por meio de currículos que operem com módulos integrados com o processo de trabalho e a construção de cidadania do profissional de saúde em formação (Albuquerque et al., 2008; Rôças, Monteiro, Siqueira-Batista, 2008). Outra proposta apresentada por Etges (2004) encontra, na pesquisa, um caminho para a interdisciplinaridade desejada: professores de determinada especialidade devem trabalhar diretamente com outros professores de outro ramo do saber. Esse trânsito deve ser permitido para grandes projetos de pesquisa. A formação de redes põe todos os pesquisadores em condições de igualdade, entendendo-se que um dos princípios fundamentais de organização deverá ser a liberdade. Portanto, a estrutura departamental, burocrática e basicamente autoritária por estrutura, deverá ser necessariamente abolida. A formação dos graduandos se dará por meio de projetos interdisciplinares. Sua formação será rigorosa, mas não bitolada para uma única atividade profissional, característica de uma fase do capitalismo que já passou.

$\mathrm{Na}$ atualidade, a departamentalização e a organização disciplinar não dão conta da formação profissional adequada nem para o mundo, nem para a trajetória de vida dos indivíduos. A interdisciplinaridade aponta saídas viáveis e extremamente fecundas para uma universidade composta por pessoas livres, capazes de atuar como sujeitos perante o saber que constroem, como sujeitos capazes de comunicar esse saber de forma que sua responsabilidade perante a sociedade esteja sempre presente e atuante (Etges, 2004).

Esse processo de mudança na formação traz elementos de contraposição à visão irreal de fragmentação dos saberes apresentados nos currículos disciplinares. Para Behrens (2006), a visão globalizadora exige um pensamento complexo para produzir conhecimento crítico, transformador, significativo e relevante. É nesse ponto que o paradigma da complexidade fundamenta a proposta de ruptura com o modelo de ensino-aprendizagem por disciplinas, como apresentar-se-á a seguir.

\section{Complexidade}

As especializações disciplinares apresentam progressos dispersos, fragmentando os contextos, as globalidades e as complexidades (Morin, 1991). Nessa perspectiva, cada dimensão do humano e do planeta é separada e encerrada nos vários departamentos das ciências. O enfraquecimento da percepção do global conduz ao enfraquecimento das responsabilidades (já que cada qual tende a ser responsável apenas por sua tarefa específica) e da solidariedade (os vínculos entre os cidadãos são recalcados). A especialização extrai um objeto do seu contexto, rejeita os laços e suas intercomunicações com o meio e sua característica de multidimensionalidade. Tendo em vista tais pressupostos, a fim de trazer o referencial da complexidade para o debate na formação em saúde, é mister relacioná-lo com a produção de conhecimento na sociedade moderna:

O paradigma da ciência moderna, assentado na razão, na divisão/análise e na máxima "conhecer para controlar" reduziu os problemas e suas respostas a modelos para a ação transformadora sobre a natureza e controladora da sociedade, produzindo conhecimentos disciplinares e com alto nível de especialização. Separar e reduzir têm sido máximas do paradigma moderno. Entretanto, natureza e sociedade nunca deixaram de ser complexas e o mundo atual é a expressão dessa complexidade - os problemas que nos apresentam são multidimensionais e as contradições se avolumam. O ser humano - alienado por suas próprias mãos - da natureza, passou a ameaçá-la de forma perigosa para sua própria espécie e todas as outras. Os laços de solidariedade humana se fragilizam, desfazem e contradições irredutíveis emergem no cotidiano natural e social. (Baumgarten, 2006, p.16) 
Rever essa forma de produção do conhecimento e de cuidado consigo, com o outro e com a natureza deve ser o pressuposto máximo das mudanças curriculares na saúde. Nesse contexto, deslocarse para além da lógica disciplinar é apenas um movimento coerente com a proposta de desenvolvimento em termos de complexidade do saber-fazer em saúde (Siqueira-Batista, Aleksandrowicz, 2006; Tarride, 1998). Para tal, utilizamos o referencial do pensamento complexo que, segundo Morin, Ciurana e Motta (2007, p.52), aborda um problema lógico e geral: "A complexidade diz respeito não apenas à ciência, mas também à sociedade, à ética e à política" .

A complexidade, confrontada com a mera simplificação - a qual esta não exclui, mas reposiciona - é um pensamento que postula a dialogicidade, a recursividade, a hologramaticidade (pressuposto que implica um elemento básico de um conjunto que pode conter quase a totalidade da informação sobre um fenômeno maior) e a holoscópica como seus princípios mais pertinentes. Trata-se de um espaço mental no qual não se obstaculiza, mas se revela e se desvela a incerteza. $E$ isso porque o pensamento complexo conhece os limites epistemológicos introduzidos pela ciência contemporânea. O pensamento complexo reconhece, então, que o movimento e a imprecisão são mais potentes do que um pensamento que os exclui e os desconsidera (Morin, Ciurana, Motta, 2007; Vasconcelos, 2002).

A complexidade não pressupõe um pensamento completo - esta não pode sê-lo, porque é um pensamento multidimensional e que articula. A ambiguidade do pensamento complexo é dar conta das articulações entre os domínios disciplinares fraturados pelo pensamento desagregador (Morin, Ciurana, Motta, 2007).

No domínio do pensamento complexo reconhece-se a existência de dois tipos de ignorância: aquela que não sabe e quer aprender, e aquela (mais perigosa) que acredita que o conhecimento é um processo linear, cumulativo, que avança trazendo a luz ali onde antes havia escuridão, desconsiderando que toda luz também produz sombras como efeito. Por isso, é preciso partir da extinção das falsas clarezas. Não podemos partir metodicamente para o conhecimento impulsionados pela confiança no claro e distinto, mas, pelo contrário, temos de aprender a caminhar na escuridão e na incerteza (Morin, Ciurana, Motta, 2007).

A complexidade, evidentemente, não despreza o simples, mas critica a simplificação. Nesse sentido, a complexidade não é a simplificação colocada às avessas, nem a eliminação do simples.

Diferentemente dos pensamentos simplificadores, que partem de um ponto inicial e conduzem a um ponto terminal, o pensamento daquilo que é complexo é um pensamento rotativo, espiral (Morin, Ciurana, Motta, 2007).

A partir desta breve contextualização das características do pensamento complexo, é possível encontrar coerência com a proposta de formar profissionais de saúde com base na construção de conhecimentos e práticas que integrem as dimensões biológica, psíquica, social e ecológica da vida, da mente, da sociedade e do ambiente, incluindo o desenvolvimento do que Capra (2002, p.13) chama de "uma maneira coerente e sistêmica de encarar algumas das questões mais críticas da nossa época".

Nestes termos, uma organização curricular que se disponha a ultrapassar o "cárcere" disciplinar pode ser uma proposta contra-hegemônica àquelas orientadas por uma visão maximizadora de recursos e restritiva do ponto de vista da cidadania, da integralidade e da equidade que o trabalho em saúde pode produzir (Saippa-Oliveira, Koiffman, 2004). A partir desse ponto de vista, é factível avançar na perspectiva de ultrapassar o confinamento disciplinar e apostar em desenhos curriculares para a área da saúde, alicerçados na inter/transdisciplinaridade e no pensamento complexo.

\section{Considerações finais}

A disciplina está em crise - anúncio vociferado por Foucault e Deleuze -, marca deste tempo, nos diferentes domínios da vida, incluída a educação. As instabilidades vigentes, mais do que eventos isolados, se inscrevem no âmbito de uma profunda mutação social, em direção a novas modalidades de organização (Chevitarese, Pedro, 2005), pautadas no novo "monstro" de Burroughs (Deleuze, 1992), o controle: 
O controle não é uma disciplina. Com uma estrada não se enclausuram pessoas, mas, ao fazer estradas, multiplicam-se os meios de controle. Não digo que esse seja o único objetivo das estradas, mas as pessoas podem trafegar até o infinito e "livremente", sem a mínima clausura, e serem perfeitamente controladas. Esse é o nosso futuro. (Deleuze, 1992, p.5)

Nestes termos, cabem as interrogações sobre os caminhos que ora se constroem em nome da ultrapassagem disciplinar: (1) A quais interesses servem? (2) A que lógica pertencem? (3) Em nome de quais dispositivos de poder se instituem?

Colocar-se tais questões - mais do que respondê-las, desta ou daquela maneira - é o que se impõe, sob pena de se deixar capturar em modulações (controle) enquanto se luta para se desvencilhar dos moldes (disciplinares). Nesta perspectiva, a reflexão inter/transdisciplinar e a complexidade podem ser antídotos, na medida em que ampliam possibilidades de pensar acerca dos enredamentos de técnica e poder, os quais são particularmente pregnantes na saúde.

Tal é a responsabilidade das instituições formadoras: ultrapassar a disciplina em prol de um ensinoaprendizagem mais fecundo e generoso, mas sem deslizar para as artimanhas do controle, sob pena de que se descubra, não sem sofrimento e dor, qual dos regimes, definidos por Deleuze (1992), é o mais duro: os buracos da toupeira ou os anéis da serpente.

\section{Colaboradores}

Os autores trabalharam juntos em todas as etapas de produção do manuscrito.

\section{Referências}

ALBUQUERQUE, V.S. et al. Pressupostos da construção de um novo currículo para o curso de Enfermagem. Rev. Enferm. UFPE On Line, v.2, p.397-403, 2008.

ALBUQUERQUE, V.S. et al. Integração curricular na formação superior em saúde: Refletindo sobre o processo de mudança nos Cursos do UNIFESO. Rev. Bras. Educ. Med., v.31, n.3, p.296-303, 2007.

BAUMGARTEN, M. Sociedade e conhecimento - ordem, caos e complexidade. Sociologias, v.8, n.15, p.16-23, 2006.

BEHRENS, M.A. Paradigma da complexidade: metodologia de projetos, contratos didáticos e portifólios. Petrópolis: Vozes, 2006.

BRASIL. Ministério da Saúde. Ministério da Educação. Programa Nacional de Reorientação da Formação Profissional em Saúde - Pró-Saúde. Brasília: Ministério da Saúde, 2005.

CAPRA, F. As conexões ocultas: Ciência para uma vida sustentável. São Paulo: Cultrix, 2002.

CHEVITARESE, L.P.; PEDRO, R.M.L.R. Da sociedade disciplinar à sociedade de controle: a questão da liberdade por uma alegoria de Franz Kafka, em O Processo, e de Phillip Dick, em Minority Report. Est. Sociol. (UFPE), v.8, n.1, p.129-62, 2005.

CREMA, R. Além das disciplinas: reflexões sobre transdisciplinaridade geral. In: WEIL, P.; D'AMBRÓSIO, U.; CREMA, R. (Orgs.). Rumo à nova transdisciplinaridade: sistemas abertos de conhecimento. 3.ed. São Paulo: Summus, 1993. p.125-73.

DELEUZE, G. Conversações. São Paulo: Edições 34, 1992. 
DELLAROZA, M.S.G.; VANNUCHI, M.T.O. (Orgs.). O currículo integrado do curso de Enfermagem da Universidade Estadual de Londrina: do sonho à realidade. São Paulo: Hucitec, 2005.

ETGES, N.J. Ciência, interdisciplinaridade e educação. In: JANTSCH, A.P.; BIANCHETTI, L. (Orgs.). Interdisciplinaridade: para além da filosofia do sujeito. 7.ed. Petrópolis: Vozes, 2004. p. 34-49.

FAZENDA, I. Interdisciplinaridade: qual o sentido? São Paulo: Paulus, 2003.

FEUERWERKER, L.C.M. Reflexões sobre as experiências de mudança na formação de profissionais de saúde. Olho Magico, v.10, n.3, p.21-6, 2003.

Além do discurso da mudança na educação médica: processos e resultados. São Paulo: Hucitec, 2002.

FOUCAULT, M. Os intelectuais e o poder. In: de Janeiro: Graal, 2006. p.145-62. Microfísica do poder. 22.ed. Rio

A vontade do saber. Rio de Janeiro: Graal, 1977.

HOUAISS, A. Dicionário Houaiss da Língua Portuguesa. Rio de Janeiro: Objetiva, 2001.

JAPIASSU, H. O sonho transdisciplinar e as razões da filosofia. Rio de Janeiro: Imago, 2006.

LIMA, V.V.; KOMATSU, R.S.; PADILHA, R.Q. Desafios ao desenvolvimento de um currículo inovador: a experiência da Faculdade de Medicina de Marília. Interface Comunic., Saude, Educ., v.7, n.12, p.175-84, 2003.

LUCK, H. Pedagogia interdisciplinar: fundamentos teórico-metodológicos. 8.ed. Petrópolis: Vozes, 2001.

MORAES, M.C. Pensamento eco-sistêmico: educação, aprendizagem e cidadania no século XXI. Petrópolis: Vozes, 2004.

MORIN, E. Introdução ao pensamento complexo. Lisboa: Instituto Piaget, 1991.

MORIN, E.; CIURANA, E.R.; MOTTA, R.D. Educar na era planetária. 2.ed. São Paulo: Cortez, 2007.

MOSÉ, V. Educação: a briga no Rio está errada. Jornal O Globo. 26. out. 2008.

PINHEIRO, R.; MATTOS, R.A. (Orgs.). Os sentidos da integralidade na atenção e no cuidado à saúde. 4.ed. Rio de Janeiro: IMS-UERJ/Cepesc/Abrasco, 2006.

POMBO, O. Interdisciplinaridade e integração dos saberes. Liinc em revista, 2005. Disponível em: <http://www.liinc.ufrj.br/revista>. Acesso em: 9 dez. 2006.

REGO, S.T.A.; GOMES, A.P.; SIQUEIRA-BATISTA, R. Humano demasiado humano: bioética e humanização como temas transversais na educação médica. Cad. ABEM, v.3, p.24-33, 2007.

REZENDE, K.T.A. et al. Implementando as unidades educacionais do curso de Enfermagem da Famema. Interface - Comunic., Saude, Educ., v.10, n.20, p.525-35, 2006.

RÔÇAS, G.; MONTEIRO, J.A.; SIQUEIRA-BATISTA, R. O debate téorico em torno do conceito de espécie: um 'transdisciplinar' relato de experiência. Cienc. Tela, v.1, n.2, p.1-9, 2008.

RODRIGUES, M.M.; REIS, S.M.A.S. O ensino superior e a formação de recursos humanos em áreas da saúde: os desafios e tendências atuais da integração e da interdisciplinaridade. Uberlândia: Programa de Pós-Graduação em Magistério Superior do Centro Universitário do Triângulo (UNIT), 2002. (Mimeogr.) 
SAIPPA-OLIVEIRA, G.; KOIFMAN, L. Integralidade do currículo de medicina: inovar/ transformar, um desafio para o processo de formação. In: MARINS, J.J.N. (Org.). Educação médica em transformação: instrumentos para a construção de novas realidades. São Paulo: Hucitec, 2004. p.143-64.

SAIPPA-OLIVEIRA, G.; KOIFMAN, L.; PINHEIRO, R. Seleção de conteúdos, ensinoaprendizagem e currículo na formação em saúde. In: PINHEIRO, R.; CECCIM, R.B.; MATTOS, R.A. (Orgs.). Ensinar saúde: a integralidade e o SUS nos cursos de graduação na área da saúde. Rio de Janeiro: IMS-UERJ/Cepesc/Abrasco, 2006. p.205-27.

SANTOMÉ, J.T.A. Globalização e interdisciplinaridade: o currículo integrado. Porto Alegre: Artmed, 1998.

SANTOS, B.S. Pela mão de Alice: o social e o político na pós-modernidade. 3.ed. São Paulo: Cortez, 1997.

SCHRAMM, F.R. As diferentes abordagens da bioética. In: PALÁCIOS, M.; MARTINS, A.; PEGORARO, O. (Orgs.). Ética, ciência e saúde: desafios da bioética. Petrópolis: Vozes, 2002. p.10-38.

SEVERINO, A. Educação e transdisciplinaridade: crise e reencantamento da aprendizagem. Rio de Janeiro: Lucerna, 2002.

SIQUEIRA-BATISTA, R. Aprendizagem baseada em problemas: uma estratégia das sociedades de controle? In: MOÇO, E.T.M.; FALCÃO, H.B.P.T.; MIRANDA, J.F.A. (Orgs.). Reflexões sobre as mudanças curriculares na área de saúde: ativando processos. Rio de Janeiro: Publit, 2007. p.79-100.

SIQUEIRA-BATISTA, R.; ALEKSANDROWICZ, A.M.C. The immune system: understanding by means of self-organization processes. In: MEETING OF THE BRAZILIAN SOCIETY FOR IMMUNOLOGY, 31., 2006, Armação dos Búzios. Abstracts... Armação dos Búzios, 2006. p.49.

SIQUEIRA-BATISTA, R. et al. Ecologia na formação do profissional de saúde: promoção do exercício da cidadania e reflexão crítica comprometida com a existência. Rev. Bras. Educ. Med., v.33, n.2, p.58-64, 2009.

SIQUEIRA-BATISTA, R.; SIQUEIRA-BATISTA, R. Os anéis da serpente: a aprendizagem baseada em problemas e as sociedades de controle. Cienc. Saude Colet., v.14, n.4, p.1183-92, 2009.

TARRIDE, M.I. Saúde pública: uma complexidade anunciada. Rio de Janeiro: Fiocruz, 1998.

VASCONCELOS, E.M. Complexidade e pesquisa interdisciplinar. 2.ed. Petrópolis: Vozes, 2002.

VEIGA NETO, A. Foucault e a educação. 2.ed. Belo Horizonte: Autêntica, 2005.

Espaço e currículo. In: LOPES, A.C.; MACEDO, E. (Orgs.). Disciplinas e integração curricular: história e políticas. Rio de Janeiro: DP\&A, 2002. p.201-20.

ZABALLA, A. Enfoque globalizador e pensamento complexo. Porto Alegre: Artmed, 2002. 
CURRÍCULOS DISCIPLINARES NA ÁREA DE SAÚDE: ...

ALBUQUERQUE, V.S. et al. Currículos disciplinarios en el área de salud: ensayo sobre saber y poder. Interface - Comunic., Saude, Educ., v.13, n.31, p.261-72, out./dez. 2009.

El presente artículo ofrece una revisión histórica sobre la construcción del conocimiento y del poder a partir de la organización disciplinaria como base para la discusión del confinamiento del saber en disciplinas en la formación de los profesionales de salud y sus consecuencias en los modos de producir atención a la salud. Acto contínuo propone la interdisciplinariedad, la trans-disciplinariedad y el pensamiento complejo como referenciales teóricos para ultrapasar la lógica disciplinaria.

Palabras clave: Interdisciplinaridad. Transdisciplinaridad. Complejidad. Curriculum. Personal de salud. Conocimiento.

Recebido em 19/11/08. Aprovado em 02/07/09. 